\title{
THE
}

2008

\section{METAPOPULATION DYNAMICS OVERRIDE LOCAL LIMITS ON LONG-TERM PARASITE PERSISTENCE}

\author{
Karthik Ram \\ Evan L. Preisser \\ University of Rhode Island, preisser@uri.edu \\ Daniel S. Gruner \\ Donald R. Strong
}

Follow this and additional works at: https://digitalcommons.uri.edu/bio_facpubs

Terms of Use

All rights reserved under copyright.

\section{Citation/Publisher Attribution}

Ram, K. , Preisser, E. L., Gruner, D. S. and Strong, D. R. (2008), METAPOPULATION DYNAMICS OVERRIDE LOCAL LIMITS ON LONG-TERM PARASITE PERSISTENCE. Ecology, 89: 3290-3297. doi: 10.1890/ 08-0228.1

Available at: https://doi.org/10.1890/08-0228.1

This Article is brought to you for free and open access by the Biological Sciences at DigitalCommons@URI. It has been accepted for inclusion in Biological Sciences Faculty Publications by an authorized administrator of DigitalCommons@URI. For more information, please contact digitalcommons-group@uri.edu. 


\title{
METAPOPULATION DYNAMICS OVERRIDE LOCAL LIMITS ON LONG-TERM PARASITE PERSISTENCE
}

\author{
Karthik Ram, ${ }^{1,3,5}$ Evan L. Preisser, ${ }^{2}$ Daniel S. Gruner, ${ }^{3,4}$ and Donald R. Strong ${ }^{1,3}$ \\ ${ }^{1}$ Section of Evolution and Ecology, University of California, Davis, California 95616 USA \\ ${ }^{2}$ Department of Biology, University of Rhode Island, Kingston, Rhode Island 02881 USA \\ ${ }^{3}$ Bodega Marine Lab, University of California-Davis, Bodega Bay, California 94923 USA \\ ${ }^{4}$ Department of Entomology, University of Maryland, College Park, Maryland 20742 USA
}

Abstract. A simple null model, particularly germane to small and vulnerable organisms such as parasites, is that local conditions set a stage upon which larger-scale dynamics play out. Soil moisture strongly influences survival of entomopathogenic nematodes (EPN), which in turn drive trophic cascades by protecting vegetation from root-feeding herbivores. In this study, we examine the mechanisms responsible for patchy occurrence of an entomopathogenic nematode, Heterorhabditis marelatus, in a California coastal prairie. One hypothesis proposes that biotic factors such as competition and natural enemies could regulate occurrence of EPN populations. We found that fungi and other enemies of EPN, although locally potent, did not explain the patterns of incidence across sites. Abiotic factors also have strong effects on EPN persistence, especially for vulnerable free-living stages. Thus, we tested the hypothesis that patchy occurrence of EPN on a large landscape was driven by differences in soil moisture.

Our research uses long-term data on nematode incidence in combination with a landscapelevel experiment to demonstrate the lack of a correlation between soil moisture and long-term persistence. A year-long experiment showed EPN mortality was weakly correlated with soil moisture among our study sites. Thirteen years of data, however, showed that colonization rates were highly correlated with long-term persistence. Sites with highest long-term persistence experienced the highest rates of rhizosphere colonization, extinction, and turnover. As a result, we concluded that metapopulation dynamics override limitations set by local and short-term abiotic conditions to determine long-term persistence in this parasite-driven trophic cascade.

Key words: entomopathogenic nematode; host-parasite; metapopulation; microparasite; persistence; survivorship.

\section{INTRODUCTION}

Parasites can play lead roles in food webs (Lafferty et al. 2006). Despite their widespread occurrence (de Meeus and Renaud 2002) and importance in regulating predation and competition (Hatcher et al. 2006), there are very few long-term or landscape-level studies on parasite population dynamics. Perhaps the best-known factors affecting parasite persistence are abiotic conditions (Morgan et al. 2004, Tseng 2006), which can have powerful consequences for parasites with a vulnerable, free-living stage outside the host, even extirpating local populations (Decaestecker et al. 2004, Cattadori et al. 2005, Pascual and Dobson 2005). A second set of potentially powerful factors involve biotic interactions, such as competition among parasites (Dobson and Hudson 1986, Hatcher et al. 2006). Parasites, like diseases, can exist as metapopulations with local colonization and extinction (Ariey et al. 2003) being modified by interactions with the environment (Hanski 1998). Long-term persistence of the free living stage

Manuscript received 2 February 2008; revised 22 July 2008; accepted 24 July 2008. Corresponding Editor: K. D. Lafferty.

5 E-mail: ram@ucdavis.edu therefore may involve some combination of endurance of local abiotic and biotic limitations that can interact with dynamic recolonization in a metapopulation (Park et al. 2001).

We ask how abiotic conditions, natural enemies, and metapopulation dynamics interact to affect long term persistence of entomopathogenic nematodes (EPN), which are lethal parasites of insects. We studied the entomopathogenic nematode Heterorhabditis marelatus (Rhabditida: Heterorhabditidae) in the context of a subterranean trophic cascade. H. marelatus are natural enemies of a root-feeding ghost moth caterpillar (Hepialus californicus; Lepidoptera: Hepialidae), which feed within the stems and roots of the yellow bush lupine, Lupinus arboreus (Strong et al. 1999). Hepialus californicus caterpillars can destroy large stands of lupines; especially in dry years. The presence of $H$. marelatus can suppress ghost moth outbreaks and protect the lupines (Preisser and Strong 2004).

Our initial hypotheses concerned variation in abiotic and biotic conditions that could interact to generate a patchy matrix of EPN incidence among sites. For instance, natural enemies may account for differences in incidence among the sites. Nematode-trapping fungi 
are by far the most common natural enemies of nematodes in lupine rhizospheres at the study site; 12 species have been isolated from the reserve (Jaffee et al. 1996). While two of the fungal species showed weak site specificity, the other 10 showed no site fidelity. Extensive field research showed that neither fungal abundance nor diversity varied among the sites with EPN in a manner consistent with a trophic cascade (Jaffee et al. 2007, also see Appendix A).

Among the most important abiotic stresses affecting EPN are soil moisture (Koppenhofer et al. 1995), temperature (Grewal et al. 1994), soil texture, and bulk density (Gruner et al. 2007). Since EPN require high humidity to survive and disperse, moisture has long been recognized as a key factor to EPN survival (Klein 1990, Grant and Villani 2003, Preisser and Strong 2004, Preisser et al. 2005, 2006). Heterorhabditis species lack the metabolic machinery for an anhydrobiotic state necessary for a truly desiccation-resistant resting stage (O'Leary et al. 2001), and $H$. marelatus has as little desiccation resistance as any EPN species yet tested (Shapiro-Ilan et al. 2006). Supporting this conclusion, several studies have found that $H$. marelatus larvae, infective juveniles (IJ), quickly become locally extinct under drought conditions (Dugaw et al. 2004, Preisser et al. 2006).

Our rationale for this study comes from curiosity about the long-term patchy occurrence of $H$. marelatus populations at the Bodega Marine Reserve (Bodega Bay, California, USA). Preliminary surveys carried out in the early 1990s showed three sites with high and three sites with low average incidence (Strong et al. 1996), a pattern that has endured over time (Fig. 1). Abiotic and biotic factors could therefore interact to create a patchy matrix of $H$. marelatus occurrence.

In this study, we examine how variation in survival among sites and metapopulation dynamics affect longterm persistence. At a given site, a lupine rhizosphere is the population base for the EPN, where colonization, reproduction, and extinction are centered and from where the larvae disperse. Patches of lupine rhizospheres form metapopulations for $H$. marelatus. We experimentally measured survival over the seasonal cycles of one complete year, and combine these results with analyses of a continuous 13-yr time series on colonization and local extinction dynamics of EPN.

\section{Study System}

We conducted this study at the Bodega Marine Reserve (BMR) of the University of California-Davis, a 147-ha coastal reserve located on the coast in Sonoma County, California, USA. We chose six sites on the reserve based on discrete populations of lupines separated by tracts of grassland. The sites are Mussel Point (MP), Cove (CO), Dune (DU), Lower Draw (LD), Upper Draw (UD), and Bayshore (BS).

Detailed descriptions of this area and the natural history of the pertinent organisms are described by Strong and colleagues (1996, 1999; also see Appendix B).

\section{Materials and Methods}

We enumerated EPN populations using a standard baiting assay based on infection of larvae of the wax moth Galleria mellonella added to soil samples (Woodring and Kaya 1988, Hominick 2002). Galleria larvae are more sensitive to EPN than naturally occurring hosts (Nielsen et al. 2004). For presence/absence, defined here as incidence, we report fraction of soil samples with infected Galleria cadavers (Woodring and Kaya 1988). This technique allowed us to assay large numbers of samples over space and time.

For analysis of local density and survival, we dissected infected Galleria larvae and counted IJ that had entered from the soil (Kaya and Stock 1997). To recover surviving IJ, we repeatedly baited samples until infections decreased to $<1 \%$ of the total recovered from all previous baitings.

\section{Incidence history of $\mathrm{H}$. marelatus}

We measured incidence of $H$. marelatus on the BMR at six sites 17 times from 1993 until 2007. At each site on each sampling date, we assayed soil from the rhizospheres of 25 haphazardly chosen mature bush lupine (L. arboreus) for $H$. marelatus. If bushes died between censuses, we marked and assayed a nearby bush.

For each sample, we collected $100 \mathrm{~g}$ of soil from the top $10 \mathrm{~cm}$ of soil centered around a lupine stem, a microhabitat that contains a sizeable fraction of EPN in this and other systems (Strong et al. 1996, Lewis et al. 2002). H. marelatus decrease rapidly deeper (more than $80 \%$ are recovered in the top $10 \mathrm{~cm}$ ) into the soil and away from lupine rhizospheres (Strong et al. 1996). Incidence of $H$. marelatus in soils more than $2.5 \mathrm{~m}$ from a lupine rhizosphere never exceeded $2 \%$ and averaged about $0.1 \%$ (Strong et al. 1996). After moistening each soil sample to $20 \%\left(0.2 \mathrm{~mL} \mathrm{H}_{2} \mathrm{O} / \mathrm{g}\right.$ soil $)$ to facilitate EPN movement, we placed it into an aerated container with six Galleria larvae. After storage for one week at summer field soil temperatures of $18^{\circ} \mathrm{C}$, we classified each Galleria as alive, killed by H. marelatus, or killed by another cause (Woodring and Kaya 1988).

\section{Extinction and colonization rates}

We calculated persistence as the proportion of bushes that remained occupied between successive samplings any two time periods, scaled by the number of days elapsed. We calculated colonization and extinction rates between consecutive samplings time periods as the proportion of bushes that changed states (unoccupied to occupied for colonization and occupied to unoccupied for extinction) over the number of days elapsed. Bushes that died between census events were not included in persistence calculations. Our bioassay has a very low rate of false negatives. In lupine rhizospheres EPN were almost always present in the first of five consecutive collected samples ( 39 of 40 times; $P<0.025$, $\mathrm{SE}=0.025, n=40$ samples). Galleria larvae are more

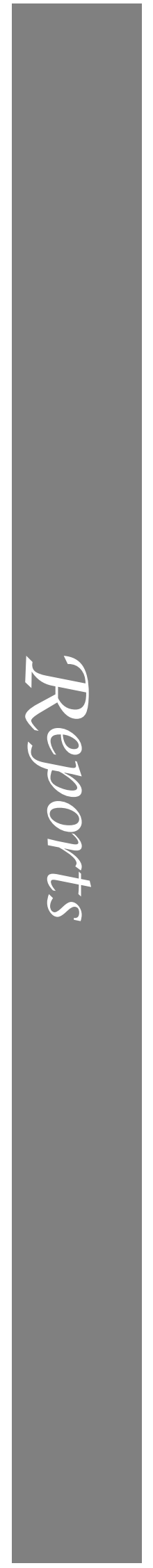




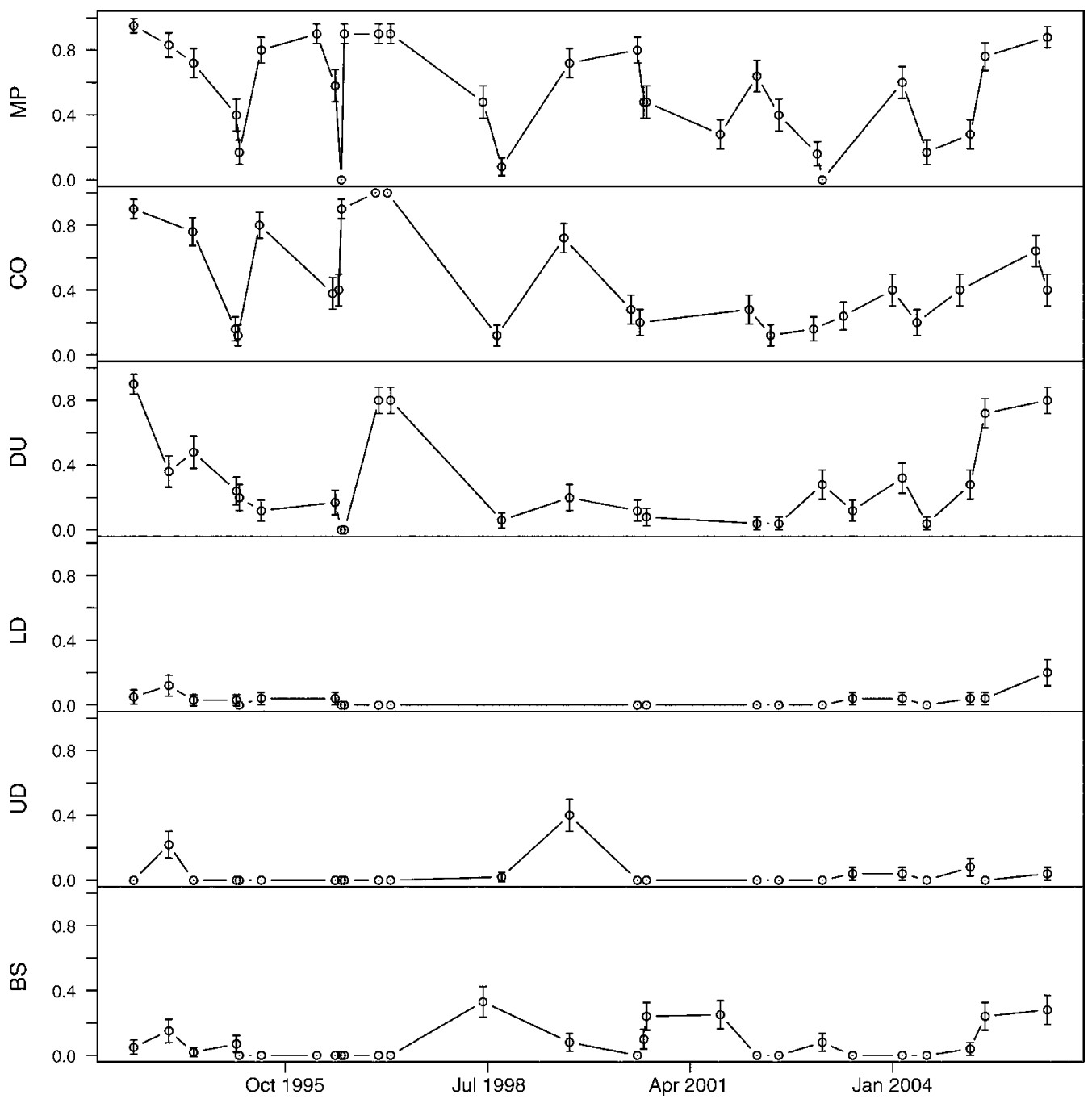

FIG. 1. Time series of long-term incidence (mean \pm SE) from 1993 to 2006. Sites are MP, Mussel Point; CO, Cove; DU, Dune; LD, Lower Draw; UD, Upper Draw; and BS, Bayshore.

sensitive to EPN than naturally occurring hosts (Nielsen et al. 2004).

\section{Survival of $\mathrm{H}$. marelatus}

In 2005, we began an experiment assessing year-long EPN survival in both annual grasslands and lupine rhizospheres at each of the six sites at BMR. We began the experiment in early summer 2005, and measured survival after 60 days in fall, at 259 days in winter, and at 351 days in late spring. The design crossed sites (six) with rhizosphere types (two), and time (three), for a total of 36 treatment combinations. Each treatment combination was replicated 40 times (total $n=1440$ ). We tracked survivorship of a known number of IJ in hostfree tubes over one year, the time period over which IJ must survive to disperse and infect hosts. Because EPN reproduction cannot occur without hosts, counts of IJ remaining in the enclosures over time accurately assesses survivorship. The experimental units were modified 50 $\mathrm{ml}$ tubes filled with pasteurized, EPN-free soil (design from Preisser et al. 2006) and contained soil isolated from the appropriate site and rhizosphere type. We placed $\sim 1100$ IJ $( \pm 4.5 \%)$ in the soil of each tube and buried them within grassland and lupine rhizospheres at each of six sites. We did not employ EPN-free control tubes in this experiment because previous work showed that EPN did not enter the tubes from the environment (Preisser et al. 2006). We enumerated surviving IJ by counting those that entered Galleria baits placed in the tubes after collection. We moistened the soil in collected tubes to $20 \%$ ( $0.2 \mathrm{ml} \mathrm{H}_{2} \mathrm{O} / \mathrm{g}$ soil) to facilitate IJ foraging, added four Galleria larvae, and incubated each tube for one week. After incubation, the Galleria were removed, assessed for symptoms of infection, and replaced with fresh Galleria baits for two more cycles. This bioassay from 12 Galleria over a 3 -wk period in each tube recovered $>99 \%$ IJ in previous trials $(\mathrm{K}$. Ram and D. 
TABLE 1. Daily extinction, colonization, turnover rates, and mean incidence from 1993 to 2006 for all six sites.

\begin{tabular}{|c|c|c|c|c|c|c|c|c|}
\hline \multirow[b]{2}{*}{ Site } & \multicolumn{2}{|c|}{ Extinction rate } & \multicolumn{2}{|c|}{ Colonization rate } & \multicolumn{2}{|c|}{ Turnover rate } & \multicolumn{2}{|c|}{ Incidence } \\
\hline & Mean & SE & Mean & SE & Mean & $\mathrm{SE}$ & Mean & $\mathrm{SE}$ \\
\hline \multicolumn{9}{|c|}{ High-incidence sites } \\
\hline MP & 0.06 & 0.01 & 0.01 & $<0.001$ & 0.57 & 0.44 & 0.52 & 0.07 \\
\hline $\mathrm{CO}$ & 0.07 & 0.01 & 0.01 & 0.00 & 1.14 & 0.07 & 0.46 & 0.07 \\
\hline DU & 0.03 & 0.00 & 0.03 & 0.00 & 3.07 & 0.32 & 0.25 & 0.06 \\
\hline \multicolumn{9}{|c|}{ Low-incidence sites } \\
\hline LD & 0.03 & 0.00 & 0.00 & $<0.001$ & 0.43 & 0.11 & 0.02 & 0.01 \\
\hline BS & 0.01 & 0.00 & 0.00 & $<0.001$ & 0.50 & 0.12 & 0.05 & 0.02 \\
\hline UD & 0.00 & $<0.001$ & 0.00 & $<0.001$ & 0.50 & 0.45 & 0.03 & 0.02 \\
\hline
\end{tabular}

Note: Abbreviations are MP, Mussel Point; CO, Cove; DU, Dune; LD, Lower Draw; UD, Upper Draw; BS, Bayshore.

Strong, unpublished data). We dissected infected cadavers and counted all IJ inside (Kaya and Stock 1997).

Our response variable, the number of surviving $H$. marelatus isolated from tube enclosures, is generally overdispersed and skewed toward zeros (Preisser et al. 2006). Therefore, we analyzed survival data with a negative binomial model (White and Bennetts 1996). The binomial model is

$$
P(Y=y)=\left(\frac{r+y-1}{y}\right)\left(\frac{r}{m+r}\right)^{r}\left(\frac{m}{m+r}\right)^{y} .
$$

In the model, $m$ is the mean of the distribution, $y$ is the number of surviving IJ, and $r$ is the dispersion parameter. This mean decreased with time due to EPN mortality, $m(t)=C^{-k t}$, where $C$ is the starting cohort and $k$ is the daily mortality rate. By fitting the model in SAS using PROC GENMOD, we obtained estimates for $k$. To test for model fit we used Pearson's $\chi^{2}$ statistic and examined plots of residuals for outliers. The initial density of $1100 \mathrm{IJ}$ was approximate owing to $4.5 \%$ experimental error in the counting and transferring IJ to the tubes. Just as the propagules of all microparasites, IJ experience very heavy mortality when they initially enter the soil (Smits 1996). Given this variability in initial numbers in the tubes, we did not specify EPN initial densities but allowed the models to fit intercepts. We took the mean of the negative binomial fit for the treatment combination of site and rhizosphere type as our estimate of mortality at different time intervals.

Prior to adding Galleria larvae and water, we measured gravimetric soil moisture in 10 tubes in each treatment combination by removing and weighing $3-5 \mathrm{~g}$ of soil, then drying it at $60^{\circ} \mathrm{C}$ for two days and reweighing it. As our moisture data were not normally distributed, we used a non-parametric ANOVA (PROC NPAR1WAY [SAS Institute 1999]) to assess the differences in moisture among sites.

\section{RESUlts}

\section{History of EPN incidence among sites}

Incidence varied by more than an order of magnitude among the study sites over 13 years (Fig. 1, Appendix C). Neither means nor peaks of incidence were correlated by distance among the sites, and proximity of sites had no effect on the patterns in the data (Fig. 1). There was also no temporal autocorrelation in the incidence data for each site $(P$ values generated by Ljung-Box tests were all nonsignificant). The closest pair of sites (LD and UD, 200 m apart) shared low mean incidence, but the rare spikes at UD were not matched at LD (Moran's test for spatial autocorrelation among sites $=-0.068$, var $=0.13, P=0.36$ ).

\section{Colonization-extinction dynamics of EPN}

Local colonization and extinction was observed at all sites. The rates of both processes were highest in the three sites with high long-term incidence and lowest in the three sites with low long-term incidence (LD, UD, and BS; Table 1, Fig. 2). The highest average persistence occurred at MP (mean $=288.95$ days, $\mathrm{SE}=27.61, n=14$ dates): almost an order of magnitude higher than the lowest site. UD had the lowest average persistence (mean $=39.4$ days, $\mathrm{SE}=3.82, n=14$ dates). Persistence in high sites was significantly higher than the low sites $\left(F_{1,83}=28.05, P<0.001\right)$. The high long-term incidence sites also had the highest average colonization rates; however, incidence and colonization rate did not rank similarly. In rank order, we measured the highest colonization rate at DU (mean $=0.029, \mathrm{SE}=0.0020, n$ $=14$ dates) followed by $\mathrm{CO}$ (mean $=0.011, \mathrm{SE}=0.0010$, $n=14$ dates $)$ and MP (mean $=0.007, \mathrm{SE}=0.0007, n=14$ dates). Colonization rates in the remaining sites were almost identically low and indistinguishable from zero.

We also measured the highest average local extinction rate at $\mathrm{DU}($ mean $=0.0283, \mathrm{SE}=0.0026, n=14)$, which was an order of a magnitude higher than the lowest site, $\mathrm{LD}($ mean $=0.0012, \mathrm{SE}=0.0001, n=14)$. Average turnover rates were higher in the three high-incidence sites $(\mathrm{DU}$ mean $=3.07, \mathrm{SE}=1.24, n=14$; $\mathrm{CO}$ mean $=$ $1.14, \mathrm{SE}=2.15, n=14$; $\mathrm{MP}$ mean $=0.6, \mathrm{SE}=1.99, n=$ 14) than in the three low-incidence sites (UD mean $=0.5$, $\mathrm{SE}=0.89, n=14 ; \mathrm{LD}$ mean $=0.5, \mathrm{SE}=0.56, n=14 ; \mathrm{BS}$ mean $=0.42, \mathrm{SE}=0.89, n=14)$.

\section{Site-specific survival}

We measured EPN survival in the field through the end of the wet season, which is the length of time

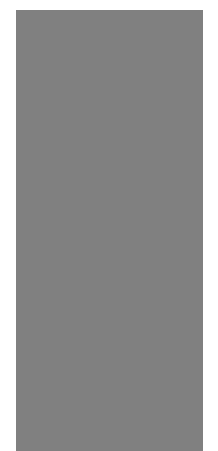

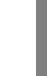



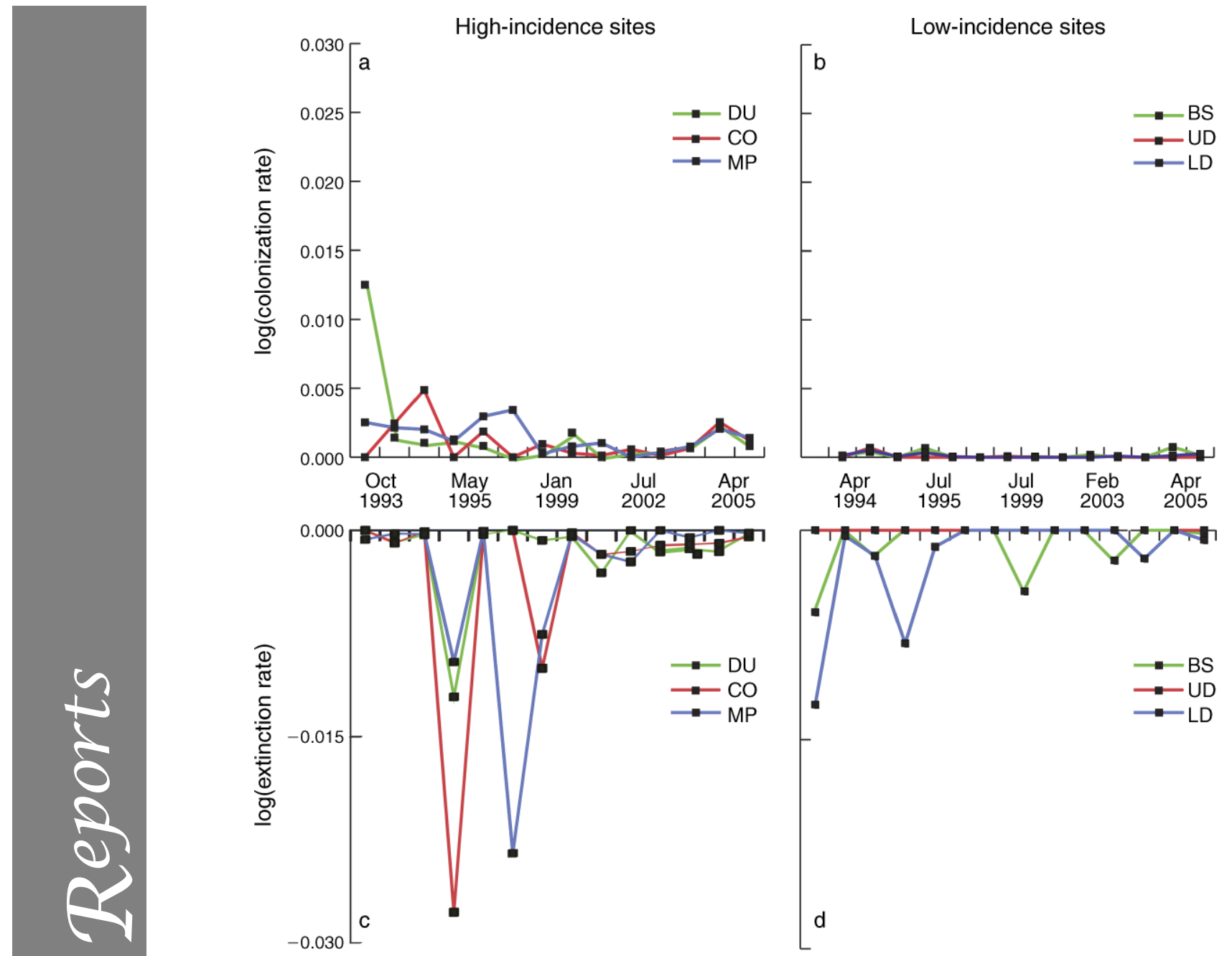

FIG. 2. Colonization and extinction rates of entomopathogenic nematodes (EPN) grouped by long-term incidence. Panels (a) and (c) represent the three high-incidence sites (MP, CO, and DU), and panels (b) and (d) represent the low-incidence sites (LD, $\mathrm{UD}$, and BS).

available to infect the next generation of their seasonal univoltine insect hosts. Using the total aggregate dataset over the course of one year, the daily mortality rate $(k)$ under lupines $(k=0.0014 \pm 0.0006 / \mathrm{d})$ was approximately half that from under grasslands $(k=0.0033 \pm$ $0.0007 / \mathrm{d}$; also see Appendix D). Daily mortality rates in both rhizosphere types were significantly elevated at DU (Appendix E, Fig. 1), while the other five sites were not statistically different (lupine, DU, $0.0093 \pm 0.0021 / \mathrm{d}$; other sites, $0.00154 \pm 0.0061 / \mathrm{d}$; grassland, DU, 0.0151 $\pm 0.0035 / \mathrm{d}$; other sites, $0.00458 \pm 0.014 / \mathrm{d}$ ).

\section{Soil moisture}

Soil moisture within tubes differed significantly among sites both under lupines $\left(\chi^{2}=37.33, \mathrm{df}=5, P\right.$ $<0.0001)$ and under grasslands $\left(\chi^{2}=25.79, \mathrm{df}=5, P<\right.$ $0.0001)$ as measured by Friedman's test. Moisture also differed among sample periods in both rhizosphere types (lupine, $\chi^{2}=226.09$, $\mathrm{df}=2, P<0.0001$; grassland, $\chi^{2}=$ 210.85, df $=2, P<0.0001)$.

The expected negative correlations between moisture and mortality among the six sites did not occur. For lupine rhizospheres, the correlation was positive among the six sites for the first sample $(r=0.55$, not significant $[\mathrm{ns}])$, very low for the second sample $(r=-0.14$, ns), and distinctly negative in the third sample $(r=-0.92, P<$ $0.01)$ with roughly equal leverage among the sites for this sample. For grassland rhizospheres, the correlation was low for the first sample $(r=-0.28$, ns) and high but highly leveraged by the DU site for the second ( $r=$ $-0.87)$ and third $(r=-0.83, P<0.01)$ samples. There was no concordance in soil moisture among sites (Friedman $\chi^{2}=6.4$, df $=5, P=0.2690$ ).

Composite of moisture, mortality, and incidence

The composite data rejected a causal chain from soil moisture through nematode survival to long-term 


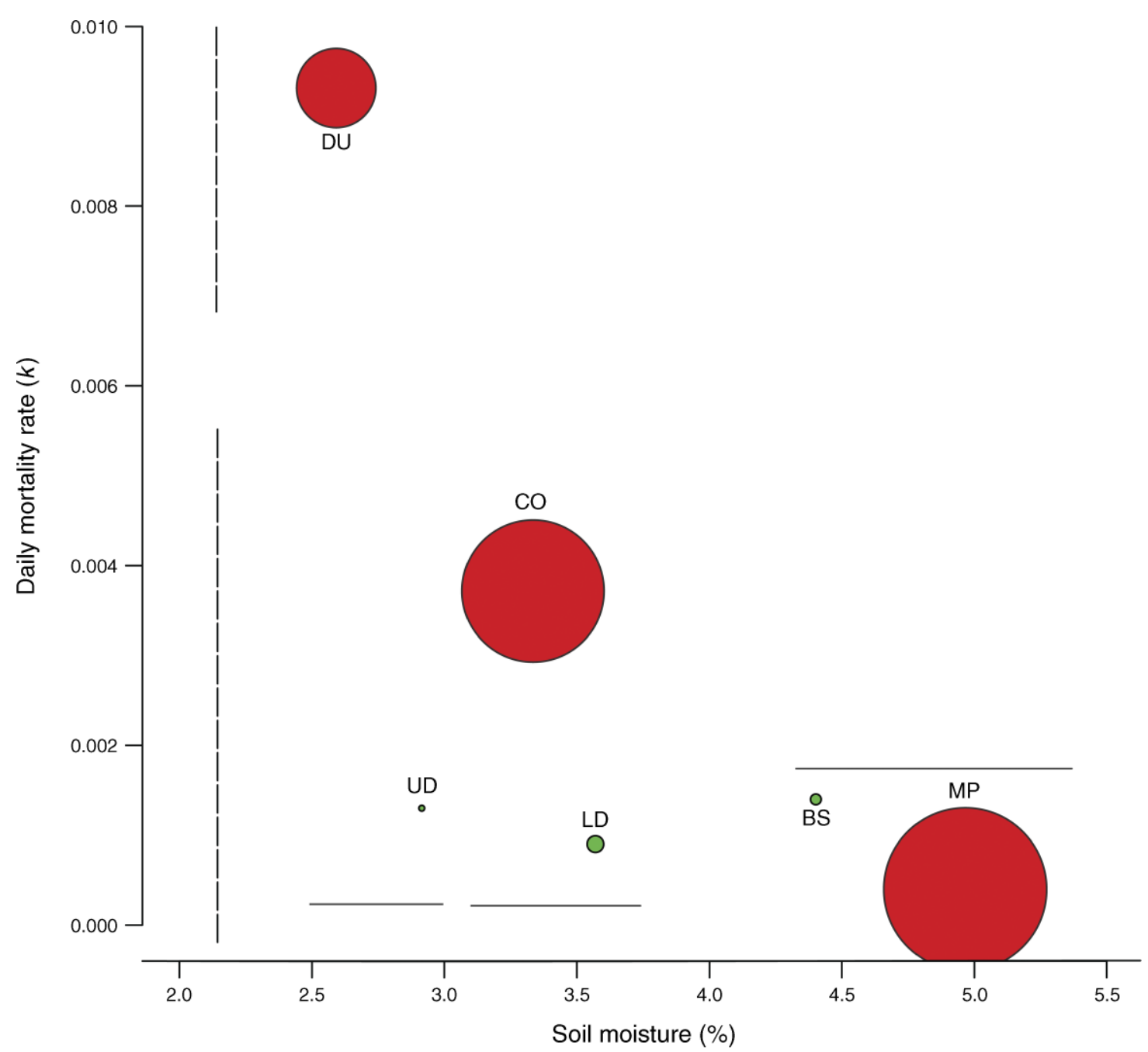

FIG. 3. Relationship between soil moisture percentage and mortality rate in lupine rhizospheres. Bubble size is directly proportional to average long-term incidence. A Tukey comparison (solid horizontal lines) on soil moisture reveals three groups (UD and MP; BS and CO; and DU and LD). A similar comparison of mortality (dashed vertical lines) reveals two groups (DU; and $\mathrm{BS}, \mathrm{LD}, \mathrm{UD}, \mathrm{CO}$, and MP).

incidence at the landscape level $(r=-0.174, P=0.741)$. The year-long experiment showed high variation in mortality among sites but without correlation with either moisture or mean long-term incidence (Fig. 3). The sites with highest long-term incidence (DU, CO, and MP) spanned the moisture spectrum from dry to wet, and their mortality rates ranged from the highest to the lowest observed. The low-incidence sites spanned the range of soil moisture and clustered at low end of IJ mortality. In sum, soil dryness did not explain the proximate variable of mortality rate, and it did not account for the patterns of long-term incidence among sites. Metapopulation with dynamics turnover of colonization and extinction are consistent with the data that these parasites exist as a metapopulation on the landscape.

\section{DisCUSSION}

Stress is well-established as important to the population and community properties of natural enemies in food chains (Menge and Sutherland 1987), in predator-prey interactions (Walde 1986), and in parasite-host ecology (Rohde and Heap 1996, Lafferty and Kuris 1999, Preisser et al. 2006). While a range of studies have found abiotic conditions can affect the ability of parasites to suppress their hosts (Lafferty and Kuris 1999), our study suggests that landscape metapopulation dynamics can override abiotic conditions for the microparasite $H$. marelatus. While it is well established that soil moisture increases EPN survival at the scale of a single rhizosphere (Preisser et al. 2006), here we examine how variation in moisture

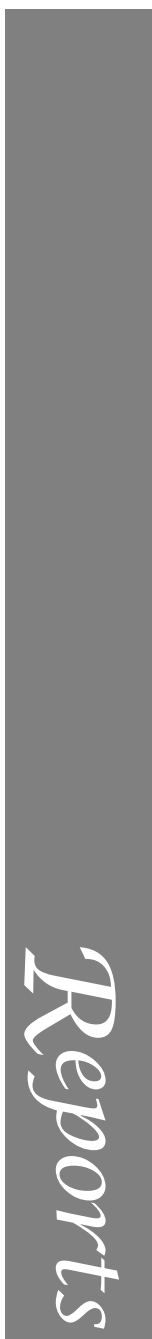


among sites affects survival and consequently longterm incidence.

Our study rejects the null hypothesis that variation in soil moisture affects mortality thereby creating heterogeneity in long-term persistence. We found high longterm incidence in sites where mortality rates are unusually high and abiotic conditions (moisture) are well below favorable levels (DU). On the contrary, we also record sites where long-term incidence has been low despite low mortality and favorable abiotic conditions (BS). Given that hosts are not variable across the monitored sites (Strong et al. 1996), our results suggest a "paradox" of parasite persistence.

EPN populations at different sites waxed and waned independently (Fig. 1). They became extirpated from some lupine rhizospheres while (re)colonizing both new and previously-inhabited rhizospheres. The dynamic behavior of EPN populations in nature is consistent with their unstable mathematical features (Dugaw et al. 2004). The lack of coordination in time of turnover events implies that climate was not the primary driver of the local dynamics of $H$. marelatus. The results show that spatial variation in soil moisture, generally considered the primary abiotic determinant of EPN persistence, does not account for the observed larger-scale spatial variation in EPN incidence. At the same time, on small scales in rhizospheres within these sites, low soil moisture causes high mortality and low persistence (Preisser et al. 2006).

The lack of correlation between survivorship and EPN incidence, together with the high correlation between colonization and incidence, provides strong evidence that the system is a dynamic metapopulation (Hanski 1999). Local extinction was followed by recolonization at most sites. Sites unfavorable for long-term persistence due to locally high extinction rates can have high incidence due to rescue by colonization from other sites in the metapopulation (Brown and Kodric-Brown 1977). Such a rescue effect is the most logical explanation at the Dune, where incidence is high despite low survivorship and moisture. The converse is also possible. A favorable site with local conditions conducive to long-term persistence may have low incidence even with limited colonization (Poulin and Morand 1999). Bayshore is such a site where incidence was historically low despite falling with Mussel Point at the high end of the moisture spectrum.

Metapopulation dynamics provide a reasonable explanation of our data. While abiotic conditions proximately affect mortality, they do not explain the largerscale patterns among sites on the landscape. We are endeavoring to understand the role of soil types (through common-garden experiments) and EPN dispersal to improve our understanding of host-parasite metapopulations. The combination of autecology with colonization and extinction dynamics add another dimension to our understanding of host-pathogen interactions and persistence.

\section{ACKNOWLEDGMENTS}

We are grateful to C. Teufel and J. McLaughlin for providing support in the field and lab. We also thank C. Dugaw and B. Dennis for statistical advice. J. Rosenheim, D. Spiller, and J. McLaughlin provided helpful comments on earlier drafts of the manuscript. This project was funded by NSF grants (DEB-0620475 and DEB-9508673) to D. R. Strong and by grants from the University of California Natural Reserve System and UC Davis Center for Population Biology to K. Ram. This is contribution \#2423 of the Bodega Marine lab, University of California-Davis.

\section{Literature Cited}

Ariey, F., J.-B. Duchemin, and V. Robert. 2003. Metapopulation concepts applied to falciparum malaria and their impacts on the emergence and spread of chloroquine resistance. Infection, Genetics and Evolution 2:185-192.

Brown, J. H., and A. Kodric-Brown. 1977. Turnover rates in insular biogeography: effects of immigration on extinction. Ecology 58:445-449.

Cattadori, I. M., B. Boag, O. N. Bjornstad, S. J. Cornell, and P. J. Hudson. 2005. Peak shift and epidemiology in a seasonal host-nematode system. Proceedings of the Royal Society B 272:1163-1169.

Decaestecker, E., C. Lefever, L. De Meester, and D. Ebert. 2004. Haunted by the past: evidence for dormant stage banks of microparasites and epibionts of Daphnia. Limnology and Oceanography 49:1355-1364.

de Meeus, T., and F. Renaud. 2002. Parasites within the new phylogeny of eukaryotes. Trends in Parasitology 18:247-251.

Dobson, A. P., and P. J. Hudson. 1986. Parasites, disease and the structure of ecological communities. Trends in Ecology and Evolution 1:11-15.

Dugaw, C. J., A. Hastings, E. L. Preisser, and D. R. Strong. 2004. Seasonally limited host supply generates microparasite population cycles. Bulletin of Mathematical Biology 66:583594.

Grant, J. A., and M. G. Villani. 2003. Soil moisture effects on entomopathogenic nematodes. Environmental Entomology 32:80-87.

Grewal, P. S., S. Selvan, and R. Gaugler. 1994. Thermal adaptation of entomopathogenic nematodes - niche breadth for infection, establishment, and reproduction. Journal of Thermal Biology 19:245-253.

Gruner, D. S., K. Ram, and D. R. Strong. 2007. Soil mediates the interaction of coexisting entomopathogenic nematodes with an insect host. Journal of Invertebrate Pathology 94:1219.

Hanski, I. 1998. Metapopulation dynamics. Nature 396:41-49.

Hanski, I. 1999. Habitat connectivity, habitat continuity, and metapopulations in dynamic landscapes. Oikos 87:209-219.

Hatcher, M. J., J. T. A. Dick, and A. M. Dunn. 2006. How parasites affect interactions between competitors and predators. Ecology Letters 9:1253-1271.

Hominick, W. 2002. Biogeography. Pages 115-143 in R. Gaugler, editor. Entomopathogenic nematology. CABI, New York, New York, USA.

Jaffee, B. A., J. L. Bastow, and D. R. Strong. 2007. Suppression of nematodes in a coastal grassland soil. Biology and Fertility of Soils 44:19-26.

Jaffee, B. A., D. R. Strong, and A. E. Muldoon. 1996. Nematode-trapping fungi of a natural shrubland: tests for food chain involvement. Mycologia 88:554-564.

Kaya, H. K., and S. P. Stock. 1997. Techniques in insect nematology. Page 281-324 in L. A. Lacey, editor. Manual of techniques in insect pathology. Academic Press, San Diego, California, USA.

Klein, M. G. 1990. Efficacy against soil-inhabiting insect pests. Pages 195-231 in R. Gaugler and H. K. Kaya, editors. 
Entomopathogenic nematodes in biological control. CRC Press, Boca Raton, Florida, USA.

Koppenhofer, A. M., H. K. Kaya, and S. P. Taormino. 1995. Infectivity of entomopathogenic nematodes (Rhabditida, Steinernematidae) at different soil depths and moistures. Journal of Invertebrate Pathology 65:193-199.

Lafferty, K. D., A. P. Dobson, and A. M. Kuris. 2006. Parasites dominate food web links. Proceedings of the National Academy of Sciences (USA) 103:11211-11216.

Lafferty, K. D., and A. M. Kuris. 1999. How environmental stress affects the impacts of parasites. Limnology and Oceanography 44:925-931.

Lewis, E. E., D. I. Shapiro-Ilan, and C. McCoy. 2002. Development rates in entomopathogenic nematodes: infected hosts vs. aqueous suspension. Journal of Nematology 34: 340-342.

Menge, B. A., and J. P. Sutherland. 1987. Community regulation: variation in disturbance, competition, and predation in relation to environmental stress and recruitment. American Naturalist 130:730-757.

Morgan, E. R., E. J. Milner-Gulland, P. R. Torgerson, and G. F. Medley. 2004. Ruminating on complexity: macroparasites of wildlife and livestock. Trends in Ecology and Evolution 19:181-188.

Nielsen, O., I. M. Skovgaard, and H. Philipsen. 2004. Estimating the incidence of entomopathogenic nematodes in soil by the use of bait insects. Nematology 6:891-900.

O'Leary, S. A., A. P. Power, C. M. Stack, and A. M. Burnell. 2001. Behavioural and physiological responses of infective juveniles of the entomopathogenic nematode Heterorhabditis to desiccation. Biocontrol 46:345-362.

Park, A. W., S. Gubbins, and C. A. Gilligan. 2001. Invasion and persistence of plant parasites in a spatially structured host population. Oikos 94:162-174.

Pascual, M., and A. Dobson. 2005. Seasonal patterns of infectious diseases. Public Library of Science Medicine 2:18-20.

Poulin, R., and S. Morand. 1999. Geographical distances and the similarity among parasite communities of conspecific host populations. Parasitology 119:369-374.

Preisser, E. L., C. J. Dugaw, B. Dennis, and D. R. Strong. 2005. Long-term survival of the entomopathogenic nematode
Heterorhabditis marelatus. Environmental Entomology 34: 1501-1506.

Preisser, E. L., C. J. Dugaw, B. Dennis, and D. R. Strong. 2006 Plant facilitation of a belowground predator. Ecology 87: $1116-1123$.

Preisser, E. L., and D. R. Strong. 2004. Climate affects predator control of an herbivore outbreak. American Naturalist 163: 754-762.

Rohde, K., and M. Heap. 1996. Latitudinal ranges of teleost fish in the Atlantic and Indo-Pacific Oceans. American Naturalist 147:659-665.

SAS Institute. 1999. SAS Version 8.00. SAS Institute, Cary, North Carolina, USA.

Shapiro-Ilan, D. I., R. J. Stuart, and C. W. McCoy. 2006. A comparison of entomopathogenic nematode longevity in soil under laboratory conditions. Journal of Nematology 38:119129.

Smits, P. H. 1996. Post-application persistence of entomopathogenic nematodes. Biocontrol Science and Technology 6: 379-387.

Strong, D. R., H. K. Kaya, A. V. Whipple, A. L. Child, S. Kraig, M. Bondonno, K. Dyer, and J. L. Maron. 1996. Entomopathogenic nematodes: natural enemies of rootfeeding caterpillars on bush lupine. Oecologia 108:167-173.

Strong, D. R., A. V. Whipple, A. L. Child, and B. Dennis. 1999. Model selection for a subterranean trophic cascade: Rootfeeding caterpillars and entomopathogenic nematodes. Ecology 80:2750-2761.

Tseng, M. 2006. Interactions between the parasite's previous and current environment mediate the outcome of parasite infection. American Naturalist 168:565-571.

Walde, S. J. 1986. Effect of an abiotic disturbance on a lotic predator-prey interaction. Oecologia 69:243-247.

White, G. C., and R. E. Bennetts. 1996. Analysis of frequency count data using the negative binomial distribution. Ecology 77:2549-2557.

Woodring, K., and H. Kaya. 1988. Steinernematid and Heterorhabditid nematodes: a handbook of biology and techniques. Arkansas Agricultural Experimental Station, Fayetteville, Arkansas, USA.

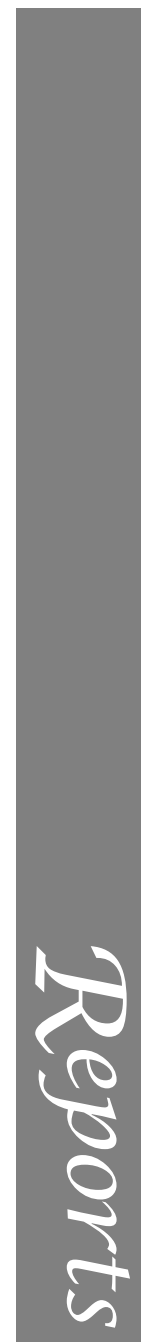

\section{APPENDIX A}

Natural enemies of EPN at Bodega Marine Reserve (Ecological Archives E089-189-A1).

\section{APPENDIX B}

Description of sites and BML habitats (Ecological Archives E089-189-A2).

APPENDIX C

Average long-term incidence from 1993-2006 (Ecological Archives E089-189-A3).

\section{APPENDIX D}

The effect of rhizosphere and site on EPN survival (Ecological Archives E089-189-A4).

\section{APPENDIX E}

Mortality estimates by site and rhizosphere type (Ecological Archives E089-189-A5). 